Original article

\title{
ANTIMICROBIAL SUSCEPTIBILITY PATTERNS OF ESCHERICHIA COLI ISOLATES FROM COCKROACHES IN SOUTHWESTERN IRAN
}

\author{
P. GHASEMI-DEHKORDI ${ }^{1}$, A. DOOSTI ${ }^{2}$, E. DOOSTI ${ }^{2}$, \\ E. NOSHADI ${ }^{2} \&$ A. ARSHI ${ }^{2}$ \\ ${ }^{1}$ Cellular and Molecular Research Center, Shahrekord University of Medical \\ Sciences, Shahrekord, Iran; ${ }^{2}$ Biotechnology Research Center, Islamic Azad \\ University, Shahrekord Branch, Shahrekord, Iran
}

\section{Summary}

Ghasemi-Dehkordi, P., A. Doosti, E. Doosti, E. Noshadi \& A. Arshi, 2016. Antimicrobial susceptibility patterns of Escherichia coli isolates from cockroaches in southwestern Iran. Bulg. J. Vet. Med., 19, No 1, 63-71.

In recent years antibiotic-resistant bacteria including those producing extended-spectrum $\beta$ lactamases increase, which could affect their pathogencity and lead to many disease in both humans and animals. Enterobacteriaceae commonly express plasmid-encoded $\beta$-lactamases family like TEM- 1 gene, which encodes resistance to penicillin in Escherichia coli. Insects, especially cockroaches, are important vectors to spread these bacteria in human living environmment. The present study was performed to evaluate the frequency of extended spectrum $\beta$-lactamase producing gene TEM- 1 and the antimicrobial susceptibility patterns of Escherichia coli strains isolated from cockroaches in Iran using antibiogram and molecular techniques. In this study, 110 cockroaches (Periplaneta americana) were collected from residential environments in Chahrmahal Va Bakhtiari province (Southwest Iran) and after bacterial culture on specific media the antimicrobial susceptibility patterns of isolated Escherichia coli strains from cockroaches were evaluated by disk diffusion test and molecular assay. The amplification of TEM-1 gene by PCR revealed a 296 bp fragment on gel electrophoresis. The results of the present research showed that Escherichia coli infection was detected in 84 samples (76.36\%) and 11 samples had the TEM-1 gene (10\%). The antibiotic susceptibility pattern using the disk diffusion test indicated that most Escherichia coli isolates from cockroaches were sensitive to imipenem $(100 \%)$ and amikacin $(87.8 \%)$, while resistance to aztreonam, ceftazidime, and ceftriaxone was $88.1 \%, 80.5 \%$, and $78.2 \%$, respectively. These findings showed that cockroaches are important agents for transmission of Enterobacteriaceae and that extended-spectrum $\beta$-lactamases producing genes like TEM-1 by Escherichia coli could increase the gastrointestinal infections and antibiotic resistance. So, antibacterial drugs such as aztreonam, ceftazidime, and ceftriaxone must be used with caution, while imipenem and amikacin antibiotics are helpful to reduce Escherichia coli infection caused by cockroaches.

Key words: cockroach, disk diffusion, Escherichia coli, extended-spectrum $\beta$-lactamases, molecular technique, TEM-1 gene 


\section{INTRODUCTION}

Cockroaches have been on earth for more than 270 million years, and are the world's most usual insects. Approximately thirty of over 4,500 identified species of this insect in the world live close to humans (Chamavit et al., 2011). Most commonly, these are the German cockroach (Blattella germanica) and the American cockroach (Periplaneta americana) (Gonzalez-Domenech et al., 2012). Cockroaches generally prefer humid, warm, and dark areas like bathrooms, kitchens, and garages. In hospitals and houses they cause serious health problems by contaminating the food and kitchenware with their saliva and waste (Feizhaddad et al., 2012; Dehghani al., 2014). The presence of cockroaches has health implications, like health facility infection, because the insects move freely from areas around hospitals, which can harbour morbific organisms (Zarchi \& Vatani, 2009). In homes and in places with poor standards of hygiene, serious infestations by cockroaches like peridomestic American cockroach (Periplaneta americana) and also the domestic German cockroach (Blattella germanica) (Feizhaddad et al., 2012) can occur. Infectious diseases and their treatment are significant issues in mankind's life and in recent years increasing of microorganism resistance has raised patients' expenses. These pests can serve as carriers, reservoirs and hosts of about 40 different species of pathogenic microorganisms (Chamavit et al., 2011; Heidari Soureshjani \& Doosti, 2013; Tetteh-Quarcoo et al., 2013). Their nocturnal lifestyle and dirty habits make them ideal carriers for transmitting numerous pathogenic bacteria, such as Listeria monocytogenes, Klebsiella pneumoniae, Staphylococcus aureus, Pseudomonas aeruginosa, Shigella spp., Streptococcus spp., Salmonella spp.,
Campylobacter spp., Pseudomonas aeruginosa, and other potential pathogens (Salehzadeh et al., 2007; Kassiri et al., 2014; Doosti et al., 2015). Up to 54\% of isolates from hospital environments are found to be human pathogens.

More than $33.3 \%$ of cockroach isolates have shown resistance to antimicrobials (Mpuchane et al., 2006). There are also many different virulence factors, which are usually encoded by plasmids, chromosomes, or bacteriophages (Tham, 2012). Escherichia coli (E. coli) is a Gram-negative rod bacillus (Ramberg et $a l ., 2012)$ and can express plasmid-encoded $\beta$-lactamases including TEM-1, TEM-2, and SHV-1. TEM-1 is one of the commonest factors conferring resistance to penicillins but not to extended-spectrum cephalosporins. In the 1980s, a new group of enzymes, the extended-spectrum $\beta$-lactamases (ESBLs) are detected (Sharma et al., 2010). ESBLs are $\beta$-lactamases that hydrolyse extended-spectrum cephalosporins with an oxyimino side chain. Plasmids responsible for ESBL production frequently carry genes encoding drug resistance. Therefore, antibiotic options with respect to ESBL-producing bacteria are extremely restricted (Rupp \& Fey, 2003).

Above 100 variations and point mutations in the TEM gene have been defined. These variations are the major cause of resistance to $\beta$-lactams in these isolates (Jain \& Mondal, 2008). Over 90\% of ampicillin resistance in $E$. coli is due to the production of TEM-1. TEM-1 is capable to hydrolyse penicillins and early cephalosporins like cephaloridine and cephalothin (Patricia, 2001).

ESBLs-producing E. coli are now a serious problem of public health worldwide. However, there are still few reports on the 
prevalence of ESBL producing E. coli isolates from cockroaches and their related genes in Iran (Zaniani et al., 2012; Goudarzi et al., 2014). In recent decades, the antibiotic-resistant bacteria like those producing TEM-type enzymes and the clinical use of $\beta$-lactams and other penicillins are followed by the researchers and the medical community (Robin et al., 2007). Therefore, the objective of the present study was to investigate the prevalence of extended spectrum $\beta$-lactamase producing genes including TEM-1 among isolated E. coli from cockroaches in Iran using antibiogram test and molecular assay.

\section{MATERIALS AND METHODS}

\section{Sampling}

This study was carried out in Chaharmahal Va Bakhtiari province (southwest Iran). A total of 110 P. americana cockroaches were collected randomly from residential environments over a period of 2 months (June 2013-August 2013). The sample collection was done from kitchens, bathrooms, water carets, parking, wardrobe departments, cellar, basement, and pets and livestock whereabouts using sticky trap methods and sterile hand gloves. Then, the samples were transported immediately to the Biotechnology Research Center in separate sterile tube to avoid any contamination. The number of collected specimens from Shahrekord, Farsan, Boroujen, and Kiar were 44, 30, 21 , and 15 , respectively.

Samples preparation and antibiotic susceptibility testing

Each cockroach was frozen at $0{ }^{\circ} \mathrm{C}$ for 5-10 min, $2 \mathrm{~mL}$ of sterile physiological saline $(0.9 \%)$ was added to each test tube and the cockroaches were thoroughly shaken for $2 \mathrm{~min}$. One hundred $\mu \mathrm{L}$ of washing solution from the body of each cockroach were cultured on MacConkey agar (Merck, Germany) plates and incubated at $37{ }^{\circ} \mathrm{C}$ for 24 hours. Then, each colony was cultured by dilution method on MuellerHinton agar plates (BD, Franklin Lakes, NJ). E. coli (ATCC 25922) was used as positive control strain. The antimicrobial susceptibility profiling using the disk diffusion test was done according to the 2011 guidelines of the European Committee of Antimicrobial Susceptibility Testing (EUCAST) (Kahlmeter et al., 2006). Standard antibiotic disks (i2a, Perols Cedex, France) were used for determination of antibiotic susceptibility patterns: imipenem $(10 \mu \mathrm{g})$, amikacin $(30 \mu \mathrm{g})$, cefepime $(30 \mu \mathrm{g})$, ceftazidime $(30 \mu \mathrm{g})$, aztreonam $(30 \mu \mathrm{g})$, and ceftriaxone $(30 \mu \mathrm{g})$. The isolated bacteria after $24 \mathrm{~h}$ of incubation at $37{ }^{\circ} \mathrm{C}$ were categorised into susceptible, resistant, or intermediate by determination of inhibitor zone around disks according to the guidelines of Clinical and Laboratory Standards Institute (CLSI) published in January 2013 and CLSI breakpoints were used for minimum inhibitory concentrations (MICs) interpretation.

\section{DNA extraction}

Total DNA was extracted from each colony of cultured bacteria using QIAamp DNA Mini Kit (Qiagen GmbH, Hilden, Germany) according to the manufacturer's recommendation. The quality of extracted DNA was quantified by NanoDrop ND1000 (PeqLab) at 260/280 nm wavelength of according to the method described by Sambrook \& Russell (2001).

\section{Gene amplification}

In order to confirm the presence of TEM-1 gene in E. coli isolates from cockroaches 
the polymerase chain reaction (PCR) using specific oligonucleotide primers including TEM-1-F: 5'-TCCGCTCATGAG ACAATAACC-3' and TEM-1-R: 5'-GAC GATACACCACGCCATAATA-3' were obtained from the study of Khalaji et al. (2013). Briefly, each amplification reaction was carried out in a total volume of $25 \mu \mathrm{L}$ (final concentration between 1 and $2 \mathrm{mM}$ ) consisting of $200 \mu \mathrm{M}$ dNTP mix, $2.5 \mu \mathrm{L}$ of $10 \times$ PCR buffer, 1 unit of Taq DNA polymerase (all Fermentas, Germany), $1 \mu \mathrm{M}$ of each forward and reverse primer, and $1 \mu \mathrm{g}$ of template DNA. Two $\mu \mathrm{L}$ of sterile ultrapure deionised water instead of template DNA were used as a negative control. The micro-tubes were placed in Gradient Palm Cycler (Corbett Research, Australia) for gene amplification. The thermo-cycling conditions included initial denaturation at $95{ }^{\circ} \mathrm{C}$ for 5 min and followed by 32 cycles consisting of denaturation at $94^{\circ} \mathrm{C}$ for $1 \mathrm{~min}$, annealing at $58{ }^{\circ} \mathrm{C}$ for $1 \mathrm{~min}$, extension at $72{ }^{\circ} \mathrm{C}$ for $1 \mathrm{~min}$, and a final extension at $72{ }^{\circ} \mathrm{C}$ for $5 \mathrm{~min}$ at the end of the amplification program. PCR products were separated on $1.5 \%$ agarose gel electrophoresis. The electrode buffer was TBE (10.8 $\mathrm{g}$ of Trisbase $89 \mathrm{mM}, 5.5 \mathrm{~g}$ of $2 \mathrm{mM}$ boric acid, 4 $\mathrm{mL}$ of 0.5 M EDTA ( $\mathrm{pH}=8.0)$, combined in sufficient $\mathrm{H}_{2} \mathrm{O}$ and stirred to dissolve). PCR products $(10 \mu \mathrm{L})$ were applied to the gel. Constant voltage of $80 \mathrm{~V}$ for $30 \mathrm{~min}$ was used for products separation. The 100 bp DNA ladder (Fermentas, Germany) was used as a molecular weight marker to determine the length of the amplified fragments.

Finally the gel were stained with ethidium bromide. The gel images were obtained using UVIdoc gel documentation system (Uvitec, UK).

\section{Statistical analysis}

The frequency of TEM-1 gene and the results of antibiotic susceptibility test of $E$. coli isolated from cockroaches were collected and analysed by SPSS software version 20 (SPSS Inc. Chicago, IL, USA).

\section{RESULTS}

The antibiotic susceptibility pattern using disk diffusion test showed that $0 \%, 4.9 \%$, $69.5 \%, 80.5 \%, 88.1 \%$, and $78.2 \%$ of isolates were resistant to imipenem, amikacin, cefepime, ceftazidime, aztreonam, and ceftriaxone, respectively. The percentages of susceptible isolates were as follows: $100 \%$ to imipenem, $87.8 \%$ to amikacin, $21.8 \%$ to ceftriaxone, $19.5 \%$ to ceftazidime, $14.2 \%$ to cefepime, and $5 \%$ to aztreonam (Table 1).

The amplified fragments of TEM-1 gene of $E$. coli isolated from cockroaches by PCR on $1.5 \%$ agarose gel electrophoresis revealed bands with the length size of $296 \mathrm{bp}$ (Fig. 1).

In this study, after bacterial culture and molecular investigation 84 samples $(76.36 \%)$ were infected with $E$. coli and

Table 1. The antibiotic susceptibility patterns of $E$. coli isolates from cockroaches

\begin{tabular}{lcccc}
\hline Antibiotic disks & MIC $(\mu \mathrm{g} / \mathrm{mL})$ & Sensitive (\%) & Intermediate (\%) & Resistant (\%) \\
\hline Imipenem & $\leq 1 \geq 4$ & 100.0 & - & - \\
Amikacin & $\leq 16 \geq 64$ & 87.8 & 7.3 & 4.9 \\
Cefepime & $\leq 8 \geq 32$ & 14.2 & 16.3 & 69.5 \\
Ceftazidime & $\leq 8 \geq 32$ & 19.5 & - & 80.5 \\
Aztreonam & $\leq 8 \geq 32$ & 5.0 & 6.9 & 88.1 \\
Ceftriaxone & $\leq 2$ & 21.8 & - & 78.2 \\
\hline
\end{tabular}


$11(10 \%)$ of them were positive for TEM1 gene (Table 2).

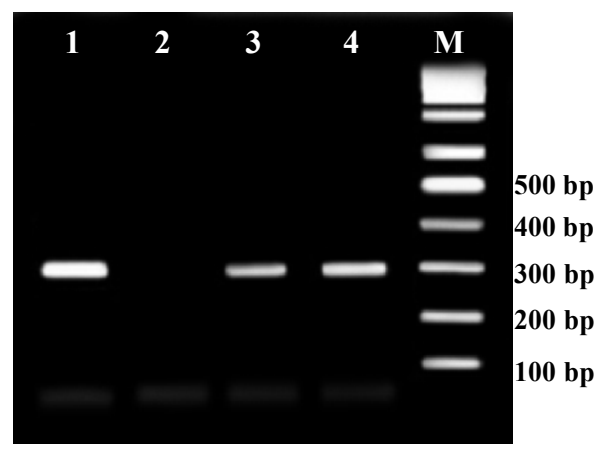

Fig. 1. The 1.5\% agarose gel electrophoresis of PCR products using specific oligonucleotide primers for detection of TEM-1 gene. Lane M: 100 bp DNA ladder (Fermentas, Germany); lane 1: E. coli ATCC 25922 (EUCAST quality control strain); lane 2: negative control (no DNA); lanes 3 and 4: amplified fragments of TEM-1 gene (296 bp).

\section{DISCUSSION}

ESBLs production rate by Enterobacteriaceae has increased perceptibly during the two recent decades (Nejati et al., 2012). The prevalence of ESBLs among Enterobacteriaceae is variable in each country. In the present study, the frequency of ESBLs producing gene included TEM-1 among $E$. coli isolated from cockroaches was investigated by the antibiogram test and molecular technique. A total of $110 P$. americana cockroaches were collected from residential environments in Chahrmahal Va Bakhtiari province (southwestern Iran). After bacterial culture and molecular investigation 84 samples $(76.36 \%)$ were infected with $E$. coli and 11 samples (10\%) were positive for TEM-1 gene.

There are different reports worldwide for outbreaks caused by ESBL bacteria. In a study on the prevalence of ESBL-producing E. coli and Klebsiella pneumoniae in Chicago, it was revealed that a common plasmid expressing TEM-1 was found in isolates from numerous patients in some hospitals (Patricia, 2001). Bell et al. (2002) indicated that the frequency of ESBL-producing $E$. coli in the medical centres located in Australia varied from $0-1 \%$ and within $13-35 \%$ for mainland Chinese centres. Moreover, the higher prevalence rates $(>20 \%)$ of ESBL $K$. pneumoniae phenotypes were observed in clinical centres. In a recent study in Iran on detection of TEM and $S H V$ genes in $K$. pneumoniae isolated from cockroaches, 32 samples $(17.87 \%)$ were positive for TEM and 15 samples $(8.37 \%)$ - positive for $S H V$ (Doosti et al., 2015). In the present research, the frequency of TEM-1 gene in isolated $E$. coli from cockroaches was $10 \%$. Investigation of $\beta$-lactamase

Table 2. Frequency of isolated $E$. coli and TEM-1 gene positive organisms in each region of the Chahrmahal Va Bakhtiari province (Southwestern Iran) using bacterial culture and molecular assay

\begin{tabular}{lccc}
\hline Regions & $\begin{array}{c}\text { Number (\%) of } \\
\text { samples }\end{array}$ & $\begin{array}{c}\text { Number (\%) of samples } \\
\text { positive for E. coli }\end{array}$ & $\begin{array}{c}\text { Number (\%) of TEM-1 } \\
\text { positive samples }\end{array}$ \\
\hline Shahrekord & $44(40.00 \%)$ & $37(84.10 \%)$ & $7(18.92 \%)$ \\
Borujen & $30(27.27 \%)$ & $21(70.00 \%)$ & $2(9.52 \%)$ \\
Farsan & $21(19.10 \%)$ & $20(95.24 \%)$ & $2(9.52 \%)$ \\
Kiar & $15(13.63 \%)$ & $6(40.00 \%)$ & - \\
\hline Total & $110(100.00 \%)$ & $84(76.36 \%)$ & $11(10.00 \%)$ \\
\hline
\end{tabular}


producing Enterobacteria isolated from German cockroaches (Blatella germanica) in hospitals of Iraq showed that the most frequent were $K$. pneumoniae $(40 \%)$, Pseudomonas aeruginosa (16.6\%), E. coli and Proteus mirabilis (each 13.3\%), Serratia marcescens $(10 \%)$ and Enterobacter aerogenes $(6.66 \%)$. In addition, all isolates were susceptible to aztreonam and ofloxacin, while in the present work $100 \%$ of $E$. coli isolates from cockroaches were susceptible to imipenem. Moreover in another study (Al-Marjani et al., 2008), 14 isolates $(46.66 \%)$ had the ability to produce $\beta$-lactamase enzymes and two isolates $(6.66 \%)$ were able to produce ESBLs. Elgderi et al. (2006) isolated 25 latent pathogen species from hospital and home cockroaches in Libya including Klebsiella, Enterobacter, Serratia and Streptococcus species. The study revealed that the place of collecting the cockroaches can affect on results according to transmitted microorganisms: Klebsiella and Enterobacter were more prevalent among the home cockroaches than in those from hospital environment (Elgderi et al., 2006). In a study done in Berkeley, USA the prevalence of ESBL bacteria was 44\% (Hawkey, 2008). In a study in Japan (Yagi et al., 2000) ESBL producers prevalence was $40 \%$, and in another study in Japan a high presence of bla $a_{\text {CTX- }}$ м-positive (CTX-M-9-group) E. coli by clonal spread was observed (Suzuki et al., 2009). In France, the incidence of this phenotype has been reported to be 30 $40 \%$ in hospitalised patients and $6 \%$ in ambulatory patients (Sirot, 1992). In some studies in southern east of Asia the outbreak of ESBL has been reported to be $20 \%$, but in some areas it has been more than 60\% (Khorshidi et al., 2011). Another research revealed that the incidence of ESBL bacteraemias was $40 \%, 18.4 \%$ in Europe and 3\% in Sweden (Coque et al., 2008).

Enterobacteria family bacteria isolates from cockroaches in Brazilian health care institutions were found in $74.6 \%$ of the samples and $96 \%$ of them were resistant to gentamicin, $84 \%$ to ampicillin, $75.3 \%$ to cephalothin, $66.7 \%$ to ampicillin-sulbactam, $50 \%$ to aztreonam and $30 \%$ to chloramphenicol (Prado et al., 2006). In the present study, $88.1 \%, 80.5 \%, 78.2 \%$, and $69.5 \%$ of $E$. coli isolates from cockroaches were resistant to aztreonam, ceftazidime, ceftriaxone, and cefepime, as well as $100 \%$ and $87.8 \%$ were sensitive to imipenem and amikacin, respectively.

The isolated microorganisms in the study of Vazirianzadeh et al. (2008) were E. coli, K. pneumoniae, Neisseria species, Bacillus cereus, Bacillus subtilis, and $S$. aureus based on sampling of external body and faeces pellets of Egyptian cockroaches in different regions of Ahvaz city (Southwest Iran). In a study carried out at the medical centres of Khorramshahr County in Iran, pathogenic microorganisms were isolated from the external surfaces of all American cockroaches: Klebsiella (47.9\%), Pseudomonas (37\%), E. coli $(30.1 \%)$, Staphylococcus $(24.6 \%)$, Enterobacter (19.2\%), Streptococcus (15.1\%), Serratia (8.2\%), Bacillus (4.1\%), and Proteus (2.7\%) (Keseler et al., 2009). In another study, E. coli strains isolated from cockroaches (Periplaneta americana) were reported as important medical infection and it was pointed out that cockroaches are potential vectors in the epidemiology of nosocomial infections. It is apparent that multiple drug-resistant bacteria of medical importance were isolated from cockroaches. These insects can act as mobile supply of such bacteria and can start a fresh prevalence of infections in neonates, life-threatening septicaemia, im- 
munocompromised patients and intensive care units (Wannigama et al., 2014).

ESBLs producing bacteria are a major global concern in the clinical and community setting. According to the findings of the present study, the increasing antibiotic resistance of bacteria like ESBLs in $E$. coli pathogenicity is important and resistance genes such as TEM-1 are risk factors for transmission of gastrointestinal infections to humans. This study revealed that imipenem and amikacin are effective antibiotics against $E$. coli isolated from cockroaches. The established antimicrobial patterns to aztreonam, ceftazidime, and ceftriaxone suggested that cockroaches can spread resistance against these antibacterial drugs, therefore they should be used with caution.

\section{ACKNOWLEDGMENTS}

This study was supported by Research Deputy of Islamic Azad University of Shahrekord Branch. The authors would like to thank all staff members of the Biotechnology Research Center of Islamic Azad University of Shahrekord Branch in Iran for their sincere support.

\section{REFERENCES}

Al-Marjani, M. F., F. N. Jafere, M. T. Abdul Hussain, E. A. Mezeal, Z. A. Sahtte, A. H. Hamza, K. J. Shanuor \& M. H. Asmaeal, 2009. Study Of B-lactamases producing Enterobacteria isolated from German cockroach (Blatella germanica) in hospitals. Diala Journal, 29, 102-112.

Bella, J. M., J. D. Turnidgea, A. C. Galesb, M. A. Pfallerc \& R. N. Jones, 2002. Prevalence of extended spectrum $\beta$-lactamase (ESBL)-producing clinical isolates in the Asia-Pacific region and South Africa: Regional results from SENTRY Antimicrobial Surveillance Program (1998-99). Diagnostic Microbiology and Infectious Disease, 42, 193-198.
Chamavit, P., P. Sahaisook \& N. Niamnuy, 2011. The majority of cockroaches from the Samutprakarn province of Thailand are carriers of parastic organisms. Experimental and Clinical Science, 10, 218-222.

Clinical and Laboratory Standards Institute (CLSI), 2013. Clinical and Laboratory Standards Institute performance standards for antimicrobial susceptibility testing, $23^{\text {rd }}$ Informational supplement (M100-S23) CLSI, Wayne, PA.

Coque, T. M., F. Baquero \& R. Canton, 2008. Increasing prevalence of ESBL-producing Enterobacteriaceae in Europe. Eurosurveillance, 13, 11.

Dehghani, R., M. Atharizadeh, S. Gh Moosavi, S. Azadi, M. Rashidi, \& A. Paksa, 2014. Analysis of cockroach fauna and frequency in human residential habitats of North of Isfahan, Iran. International Archives of Health Sciences, 1, 25-29.

Doosti, A., M. Pourabbas, A. Arshi, M. Chehelgerdi \& H. Kabiri, 2015. TEM and SHV genes in Klebsiella pneumonia isolated from cockroaches and their antimicrobial resistance pattern. Osong Public Health and Research Perspectives, 6, $3 \mathrm{e} 8$.

Elgderi, R. M., K. S. Ghenghesh \& N. Berbash, 2006. Carriage by the German cockroach (Blattella germanica) of multipleantibiotic-resistant bacteria that are potentially pathogenic to humans, in hospitals and households in Tripoli, Libya. Annals of Tropical Medicine and Parasitology, 100, 55-62.

Feizhaddad, M. H., H. Kassiri, M. R. Sepand \& F. Ghasemi, 2012. Bacteriological survey of American cockroaches in hospitals. Middle-East Journal of Scientific Research, 12, 985-989.

Gonzalez-Domenech, C. M., E. Belda, R. Patino-Navarrete, A. Moya, J. Pereto \& A. Latorre, 2012. Metabolic stasis in an ancient symbiosis: Genome-scale metabolic networks from two Blattabacterium cuenoti strains, primary endosymbionts of cockroaches. BMC Microbiology, 18, 12. 
Goudarzi, M., F. Sabzehali, Z. Tayebi, M. Azad, S. H. Boromani, A. Hashemi \& S. S. Seyedjavadi, 2014. Prevalence of bla $a_{\mathrm{CTX}-\mathrm{M}}$ gene in multi-resistant Escherichia coli isolated from urinary tract infections, Tehran, Iran. Novelty in Biomedicine, 2, 107-113.

Hawkey, P. M., 2008. Prevalence and clonality of extended-spectrum $\beta$-lactamases in Asia. Clinical Microbiology and Infections, 14, 159-165.

Heidari Soureshjani, E. \& A. Doosti, 2013. Examination methicillin-resistant Staphylococcus aureus (MRSA) prevalence in cockroaches from hospital in Chaharmahal-va-Bakhtiari province, Iran by polymerase chain reaction (PCR). International Journal of Medicine and Medical Sciences, 5, 324-329.

Jain, A. \& R. Mondal, 2008. TEM \& SHV genes in extended spectrum $\beta$-lactamase producing Klebsiella species \& their antimicrobial resistance pattern. Indian Journal of Medical Research, 128, 759-764.

Kahlmeter, G., D. F. J. Brown, F. W. Goldstein, A. P. MacGowan, J. W. Mouton, I. Odenholt, A. Rodloff, C-J. Soussy, M. Steinbakk \& F. Soriano, 2006. European Committee on Antimicrobial Susceptibility Testing (EUCAST) technical notes on antimicrobial susceptibility testing. Clinical Microbiology and Infection, 12, 501-503.

Kassiri, H., A. Kassiri \& S. Kazemi, 2014. Investigation on American cockroaches medically important bacteria in Khorramshahr hospital, Iran. Asian Pacific Journal of Tropical Disease, 4, 201-203.

Keseler, I. M., C. Bonavides-Martnez, J. Collado-Vides, S. Gama-Castro, R. P. Gunsalus, D. A. Johnson, M. Krummenacker, L. M. Nolan, S. Paley \& I. T. Paulsen. 2009. EcoCyc: A comprehensive view of Escherichia coli biology. Nucleic Acids Research, 37, 464-470.

Khalaji, Y., A. Doosti \& S. Ghorbani-Dalini, 2013. Molecular evaluation of antibiotic resistance prevalence in Pseudomonas aeruginosa isolated from cockroaches in South- west Iran. International Journal of Medicine and Medical Sciences, 5, 420-424.

Khorshidi, A., M. Rohani \& R. Moniri, 2011. The prevalence and molecular characterization of extended-spectrum $\beta$-lactamasesproducing Klebsiella pneumoniae isolates recovered from Kashan hospital university, Iran. Jundishapur Journal of Microbiology, 4, 289-293.

Mpuchane, S., I. M. Matsheka, B. A. Gashe, J. Allotey, G. Murindamombe \& N. Mrema, 2006. Microbiological studies of cockroaches from three localities in Gaborone, Botswana. African Journal of Food, Agriculture, Nutrition and Development, 6, 17.

Nejati, J., A. Keyhani, S. H. Moosa-Kazemi, M. Mohammadi, M. Mahjoob \& A. Boostanbakhsh, 2012. Cockroaches' bacterial infections in wards of hospitals, Hamedan city, west of Iran. Asian Pacific Journal of Tropical Medicine, 2, 381-384.

Patricia, A. B., 2001. Extended-spectrum $\beta$ lactamases in the 21st century: Characterization, epidemiology, and detection of this important resistance threat. Clinical Microbiology Reviews, 14, 933-951.

Prado, M. A., E. Gir, M. S. Pereira, C. Reis \& F. C. Pimenta, 2006. Profile of antimicrobial resistance of bacteria isolated from cockroaches (Periplaneta americana) in a Brazilian health care institution. Brazilian Journal of Infectious Diseases, 10, 26-32.

Ramberg, C., 2012. Molecular characterization of Norwegian clinical isolates of Escherichia coli hyperproducing the chromosomal AmpC $\beta$-lactamase; a regional spread of an IS911-mediated $\beta$-bla Amp $_{C}$-hyperexpressing ST131 clone. Master Thesis in Biomedicine, Institute of Medical Biology, University of Tromsø.

Robin, F., J. Delmas, C. Schweitzer, O. Tournilhac, O. Lesens, C. Chanal \& R. Bonnet, 2007. Evolution of TEM-type enzymes: Biochemical and genetic characterization of two new complex mutant TEM enzymes, TEM-151 and TEM-152, from a single patient. Antimicrobial Agents and Chemotherapy, 51, 1304-1309. 
Rupp M. E. \& P. D. Fey, 2003. Extended spectrum $\beta$-lactamase (ESBL)-producing Enterobacteriaceae: Considerations for diagnosis, prevention and drug treatment. Drugs, 63, 353-365.

Salehzadeh, A., P. Tavacol \& H. Mahjub, 2007. Bacterial, fungal and parasitic contamination of cockroaches in public hospitals of Hamadan. Iranian Journal of Arthropod-Borne Diseases, 44, 105e10.

Sambrook, J. \& D. W. Russell, 2001. Molecular cloning: A Laboratory Manual. $3^{\text {rd }}$ edn, Cold Spring Harbor Laboratory Press; Cold Spring Harbor, New York, pp. 148-190.

Sharma, J., M. Sharma \& P. Ray, 2010. Detection of TEM \& SHV genes in Escherichia coli \& Klebsiella pneumoniae isolates in a tertiary care hospital from India. Indian Journal of Medical Research, 137, 332336.

Sirot, D. L., F. F. W. Goldstein \& C. J. Soussy, 1992. Resistance to cefotaxime and seven other beta-lactamases in members of the family Enterobacteriaceae: A 3-year survey in France. Antimicrobial Agents and Chemotherapy, 36, 1677-1681.

Suzuki, S., N. Shibata, K. Yamane, J. Wachino, K. Ito \& Y. Arakawa, 2009. Change in the prevalence of extended-spectrum- $\beta$ lactamase-producing Escherichia coli in Japan by clonal spread. Journal of Antimicrobial Chemotherapy, 63, 72-79.

Tetteh-Quarcoo, P. B., E. S. Donkor, S. K. Attah, K. O. Duedu, E. Afutu, I. M. Boamah, Olu-Taiwo, I. Anim-Baidoo \& P. F. Ayeh-Kumi, 2013. Microbial carriage of cockroaches at a tertiary care hospital in Ghana. Environmental Health Insights, 3, 59-66.

Tham, J., 2012. Extended-spectrum beta-lactamase-producing Enterobacteriaceae: Epidemiology, risk factors, and duration of carriage. Lund University, ISBN 978-9187189-28-9.

Vazirianzadeh, B., S. S. Solary, M. Rahdar, R. Hajhossien \& M. Mehdinejad, 2008. Identification of bacteria which possible transmitted by Musca domestica (Diptera: Mus- cidae) in the region of Ahvaz, SW Iran. Jundishapur Journal of Microbiology, 1, 28-31.

Wannigama, D. L., R. Dwivedi \& A. ZahraeiRamazani, 2014. Prevalence and antibiotic resistance of Gram-negative pathogenic bacteria species isolated from Periplaneta americana and Blattella germanica in Varanasi, India. Journal of Arthropod-Borne Diseases, 8, 10-20.

Yagi, T., H. Kurokawa, N. Shibata, K. Shibayama \& Y. Arakawa, 2000. A preliminary survey of extended-spectrum $\beta$-lactamases (ESBLs) in clinical isolates of Klebsiella pneumoniae and Escherichia coli in Japan. FEMS Microbiology Letters, 184, 53-56.

Zaniani F. R., Z. Meshkat, M. Naderi Nasab, M. Khaje-Karamadini, K. Ghazvini, A. Rezaee, H. Esmaily, M. S. Nabavinia \& M. Darban Hoseini, 2012. The prevalence of $T E M$ and $S H V$ genes among extendedspectrum beta-lactamases producing $E s$ cherichia coli and Klebsiella pneumoniae. Iranian Journal of Basic Medical Sciences, 15, 654-660.

Zarchi, A. A. \& H. Vatani, 2009. A survey on species and prevalence rate of bacterial agents isolated from cockroaches in three hospitals. Vector Borne and Zoonotic Diseases, 9, 197-200.

Paper received 08.10.2014; accepted for publication 13.03.2015

\section{Correspondence:}

Abbas Doosti

Biotechnology Research Center,

Islamic Azad University, Shahrekord Branch, Rahmatieh, Shahrekord, Iran,

Postal box 166 , tel: +98-38-33361001; fax: +98-38-33361001 e-mail: biologyshki@yahoo.com 